\title{
Efficient resourcezation of sulfanilamide wastewater and A study on this reaction
}

\author{
Yingying Tian ${ }^{1.2}$, Kai Wen ${ }^{2}$ and Dezhan Chen ${ }^{1, *}$ \\ ${ }^{1}$ College of Chemistry, Chemical Engineering and Materials Science, Shandong Normal University, Jinan 250014, P. R. China \\ ${ }^{2}$ College of Resource and Environmental Engineering, Shandong Agricultural Engineering University, Jinan 250100, P. R. China
}

\begin{abstract}
Sulfanilamide wastewater which is come from the dyestuff plant is characterized by a high content of hardly biodegradable dissolved, high acidity, and organic matter. The dyestuff plant's wastewater has become a water pollution of the world's attention. Therefore, efficient removal of sulfanilic acid and hydrochloric acid from wastewater before drainage is of great importance. This paper designed a new process engineering containing a recovery of sulfanilic acid and hydrochloric acid, at the same time which can cycle the mother liquor without any wastewater. The experimental results showed that, using this new process engineering is better than that in traditional methods.
\end{abstract}

\section{Introduction}

Wastewater from dyestuff plant has a negative impact on environment and water resource. In particular, great concerns arise from sulfanilamide wastewater because it is characterized the high acidity, high concentrations of organic matter, and vast emissions[1]. Many dye factory use waste carbide slag to make neutralization treatment wastewater containing acid, then go through a solid-liquid separation process to treatment the wastewater[2]. Furthermore, some studies on using a two-phase anaerobic system sulfanilamide wastewater treatment[3] or the adsorption of resin adsorption method is adopted to aminobenzene sulfonic acid to biochemical treatment process[4]. This treatment effect is obvious, but such process'loading is small, cycle is long, which does not apply to sulfanilamide factory mass production, and there are still a lot of sewage discharge[5]. So exploration with economic benefits, being suitable for mass production, and having the environmental benefits of wastewater treatment process is particularly important. This article through to study on sulfanilamide wastewater containing acid, put forward a new post-treatment technology of waste acid water route, recycled the economic value of products, and circulate the mother liquid, basically achieved zero emissions. New process mainly steamed out of hydrochloric acid by using ammonium chloride solid-state metathesis reaction. By means of the adjustment of the temperature and solvent, precipitation in aminobenzene sulfonic acid, and effective use of SO42 - in the waste water, such as the production of ammonium sulfate sulfate products, the feasibility of this technology has a large-scale production.

\section{Experimental part}

\subsection{Reaction principle}

Sulfonamide waste acid solution, see table 1 for main components.

Table 1. Main components of sulfanilamide waste acid solution $(\%)$

\begin{tabular}{cccccc}
\hline $\mathrm{H}_{2} \mathrm{~S}$ & $\mathrm{HA}$ & $\mathrm{HC}$ & & & Sulfanil \\
$\mathrm{O}_{4}$ & $\mathrm{c}$ & 1 & amide & & \\
\hline $35 \sim 4$ & 0.8 & 0.3 & & $2 \sim 3$ & \\
0 & 4 & 7 & & & \\
\hline
\end{tabular}

Through the component analysis ,the experimental objectives were established as follows: recovery of sulfanilic acid and hydrochloric acid,a large number of $\mathrm{SO}_{4}{ }^{2}$ - in waste acid water were further synthesized into sulfate products, and the mother liquor produced was recycled.

\footnotetext{
* Corresponding author: tavis_cn@sina.com
} 


\subsection{Technological process}

The waste acid water (calculated by sulfuric acid content of $36 \%$ ) and the solid ammonium chloride are mixed in the mixing kettle at molar ratio 1:1, after mixing, it was heated and evaporated in the evaporation kettle, the pressure in the kettle was maintained at $0.05 \mathrm{MPa}$, distillate occured when the temperature of bottom residue reached $85^{\circ} \mathrm{C}$, after heating and distilling for one hour, the temperature of bottom residue continued to rise, distillate gradually disappeared, distillation was completed. More than $90 \%$ hydrochloric acid and distillation residue mainly containing ammonium bisulphate can be recovered.

$\mathrm{H}_{2} \mathrm{SO}_{4}+\mathrm{NH}_{4} \mathrm{Cl} \rightarrow \mathrm{NH}_{4} \mathrm{HSO}_{4}+\mathrm{HCl}$

$\mathrm{NH}_{4} \mathrm{HSO}_{4}$ crystals were precipitated from the distilling residue, which can be refined to produce $\mathrm{NH}_{4} \mathrm{HSO}_{4}$ products; it also can add the mother liquor to the distilling residue to produce $\left(\mathrm{NH}_{4}\right)_{2} \mathrm{SO}_{4}$ products by adding ammonia water to adjust the $\mathrm{pH}$ value of the system, and the generated ammonium sulfate mother liquor is the mother liquor.

$\mathrm{NH}_{4} \mathrm{HSO}_{4}+\mathrm{NH}_{3} \cdot \mathrm{H}_{2} \mathrm{O} \rightarrow\left(\mathrm{NH}_{4}\right)_{2} \mathrm{SO}_{4}+\mathrm{H}_{2} \mathrm{O}$

Based on the property of slight solution of sulfanilic acid in cold water, the temperature of the system was adjusted to about $20{ }^{\circ} \mathrm{C}$, and the crystal of sulfanilic acid was separated and refined.

\section{Results and discussion}

\subsection{Process conditions for evaporation of hydrochloric acid}

According to the azeotropic distillation principle of water and $\mathrm{HCl}$, hydrochloric acid in acid wastewater was recovered by adding solid ammonium chloride into acid wastewater for stirring and distillation. Under normal pressure, the boiling point of ammonium bisulfate is $490^{\circ} \mathrm{C}$, the decomposition temperature of sulfanilic acid is $280^{\circ} \mathrm{C}$, and the azeotropic temperature of water and $\mathrm{HCl}$ is $110^{\circ} \mathrm{C}[6]$. Under normal pressure, the azeotropic system of water and $\mathrm{HCl}$ can be formed at the temperature of $110^{\circ} \mathrm{C}$ without taking out ammonium bisulfate and sulfanilic acid.

\subsubsection{Distillation temperature}

Under normal pressure,the majority of hydrochloric acid can be steamed by controlling the distillation temperature at $110-140^{\circ} \mathrm{C}$; under reduced pressure, distillation temperature varies with pressure. The pressure is $0.05 \mathrm{MPa}$, the relationship between distillation time of wastewater containing acid, tower bottom and tower top temperature, $\mathrm{Cl}^{-}$concentration in bottom residue are shown in figure 1:

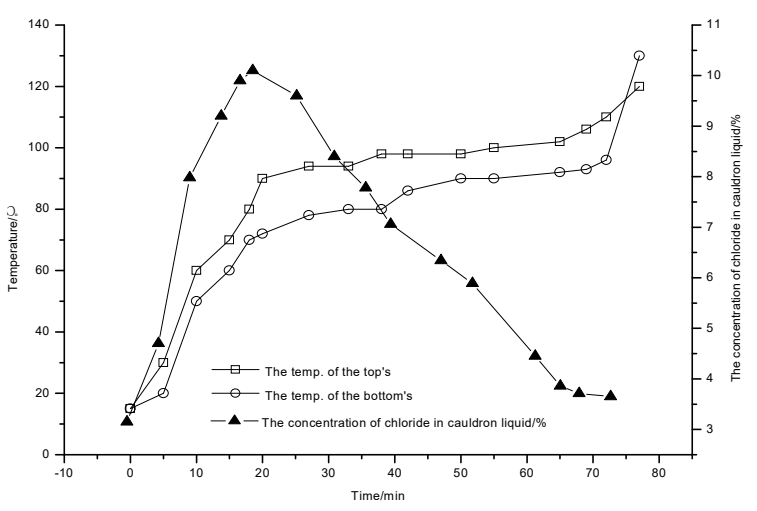

Figure 1. Relation curves of distillation time,kettle bottom and kettle top temperature, $\mathrm{Cl}$ - concentration in bottom residue

\subsubsection{Distillation pressure}

Pressure has a great influence on the evaporation rate of hydrochloric acid. Compared with normal pressure distillation, reduced pressure distillation can increase the evaporation rate of hydrochloric acid by about $20 \%$, as shown in table 2 . Through the experiment, the hydrochloric acid can be effectively evaporated by stirring and evaporation under the control of pressure in the range of -0.05 to $-0.06 \mathrm{MPa}$.

Table 2. Under different pressures, evaporation rate of hydrochloric acid at the same distillation time (\%)

\begin{tabular}{ccccc}
\hline Pressure/MPa & $\begin{array}{c}\text { ordinary } \\
\text { pressure }\end{array}$ & 0.02 & 0.04 & 0.06 \\
\hline $\begin{array}{l}\text { Hydrochloric acid } \\
\text { evaporation rate } \%\end{array}$ & 68 & 75 & 88 & 93 \\
\hline
\end{tabular}




\subsection{Ammonia is neutralized with ammonium bisulfate to produce ammonium sulfate}

The distilling residue contains a large amount of $\mathrm{NH}_{4} \mathrm{HSO}_{4}$. When the temperature is lower than $70^{\circ} \mathrm{C}$, $\mathrm{NH}_{4} \mathrm{HSO}_{4}$ can crystallize and be sold as a product; it also can add the mother liquor for dissolution and add ammonia water for neutralization to produce ammonium sulfate products.

Refer to the process of producing ammonium sulfate by direct neutralization of sulfuric acid and ammonia, the content of sulfuric acid in the system is $36 \%$, in order to obtain qualified ammonium sulfate products, the $\mathrm{pH}$ value of the system needs to be adjusted. When ammonia water is added to the mother liquor containing $40 \%$ sulfuric acid, crystals are precipitated when the $\mathrm{pH}$ of the system approaches [7]. Through the experiment, the $\mathrm{pH}$ value of the system was adjusted from 6.5 to 8.5 by adding ammonia water to monitor the precipitation amount of ammonium sulfate. When the $\mathrm{pH}$ of the system is $8 \pm 0.5$, the maximum amount of ammonium sulfate can be crystallized out, and the ammonia taste of the product is small.

\subsection{Separation of sulfanilic acid}

Through analysis, the organic matter in waste acid is in the form of sulfanilic acid. $\mathrm{N}$-acetylsulfanilic acid is soluble in water, it slowly hydrolyzes into acetic acid and sulfanilic acid in aqueous solution, the hydrolysis can be accelerated by heating. Sulfanilic acid is slightly soluble in cold water( Under normal pressure, at $10^{\circ} \mathrm{C}$, the solubility of sulfanilic acid is $0.8 \mathrm{~g} / 100 \mathrm{~g}$ water), solubility increases with temperature [8], and this property can be used to separate sulfanilic acid.

Hydrogen ions on the sulfonic acid group of sulfanilic acid in ammonium sulfate mother liquor at different $\mathrm{pH}$ values were detected by ${ }^{1} \mathrm{H}-\mathrm{NMR}$, it is concluded that the sulfanilic acid solubility in the mother liquor of ammonium sulfate under different $\mathrm{pH}$ value (see figure 2 ), and the best conditions for separation of sulfanilic acid is ammonium sulfate mother liquor $\mathrm{pH}$ is about 2, the content of sulfanilic acid is the least in solution. By adjusting the $\mathrm{pH}$ value of the system to about $2,83 \%$ of sulfanilic acid in waste acid water can be recovered.

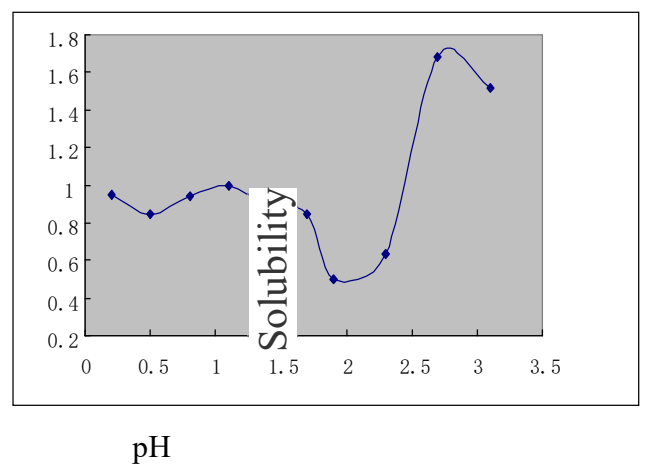

Figure 2. Solubility of p-aminobenzenesulfonic acid in ammonium sulfate mother liquor under different $\mathrm{pH}$

\section{Conclusions}

The new process can steam hydrochloric acid and recover sulfanilic acid from waste acid water by adding $\mathrm{NH}_{4} \mathrm{Cl}$ solid to sulfonamide wastewater,using $\mathrm{SO}_{4}^{2-}$ in acid wastewater to produce sulphate products to improve the economic value of sulfonamide wastewater so that sulfanilamide wastewater reach the resource treatment, at the same time,mother liquor is recycled in the system, and the whole processing process basically reaches zero discharge. This conforms to the requirements of modern chemical industry for economic, environmental and social benefits. Compared with the traditional waste acid liquor treatment, the new process has a great improvement, and has great market promotion value.

\section{References}

1. Shi Jing, Wang Hongwu, Ma Luming.Research status of sulfa wastewater treatment in China [J]. Journal of liaoning institute of technology,2006,26(5) : 326-328

2. R.M. Baena-Nogueras, E. González-Mazo, P.A. Lara-Martín.Degradation kinetics of pharmaceuticals and personal care products in surface waters: photolysis vs biodegradation Sci. Total Environ., 590 - 591 (2017), pp. 643-654,

3. Gao Jun, DIAO Litong, Li Xinjun.Study on the treatment of acid containing wastewater from sulfa production $[\mathrm{J}]$. Industrial water treatment, 1998,18 (5) : 17-18

4. Ren Nanqi, Liu Yanling, Liu Min.Experimental study on the treatment of sulfa wastewater by two-phase anaerobic system $[\mathrm{J}]$. China water \& wastewater, $2001,17(2): 8-11$

5. Sun Yue, Zhu Zhailian, PAN Bingcai.Treatment of sulfa wastewater by resin adsorption [J]. Environmental protection of chemical industry, 2003,23 (1) : 9-13

6. P. Chakraborty, M. Mukhopadhyay, S. Sampath, B.R. Ramaswamy, A. Katsoyiannis, A. Cincinelli, D. Snow Organic micropollutants in the surface riverine sediment along the lower stretch of the transboundary river Ganga: occurrences, sources and ecological risk 
assessment, Environ. Pollut., 249 (2019), pp. 10711080

7. Liu Guangqi, Ma Lianxiang, Liu Jie.Chemical chemical physical properties data manual (inorganic volume) [M]. Chemical industry press, 1998,411,477

8. Chen Shi, Meng Cong, Li Wu. Chemical safety and environmental protection, 2007,33 (2) 43-46. (in Chinese

9. Liu Guangqi, Ma Lianxiang, Liu Jie.Chemical chemical properties data manual (organic volume) [M]. Chemical industry press, 1998,26 